\title{
Photo-Clerical Experiment
}

\author{
Dr. Shaw is librarian, U. S. Department \\ of Agriculture.
}

$\mathrm{E}$

XPERIMENTATION in the Department of Agriculture Library over the last three years in the use of a camera for the performance of clerical routines, such as follow-up on book orders, overdues, or missing issues of periodicals, indicated that this new technique offers possibilities for simplification of library routines, and for improvement of library services through reduction of the amount of time which must be spent on these routines.

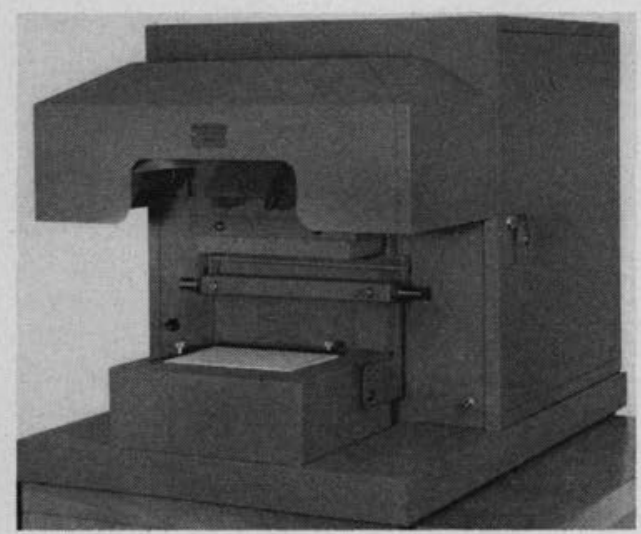

Since the savings result primarily from improvement in systems made possible through the use of the new photographic equipment, rather than from the use of the cameras alone, it is obvious that the conditions under which the cameras are used are really more important than the machines themselves in determining whether improvements in library management may be expected generally through their application.

A grant made by the Carnegie Corpora- tion of New York through the American Council of Learned Societies has made it possible to build ten of the new cameras (see figure) and processors and to experiment with them under ten different management situations.

A manual on the photoclerical processes has been prepared. Each of the cooperating libraries has undertaken to experiment with as many of the applications shown in the manual as seem feasible, and will also experiment with other applications of their own. A reporting system has been set up which will show the method used in the past for each of the experimental operations and the cost of performing each operation the old way. It will then report the new method and the costs involved under the new method. Our reporting system will let each of the cooperating libraries know what the others are doing. In setting up our experiments we have agreed that it is quite as important to know the areas in which the machine applications are not profitable as it is to learn the areas in which applications show savings in cost or improvements in service.

Since experience at the Department of Agriculture Library over several years shows that proper application of this new method to large scale operations can be very profitable, there is no need to prove this fact. Thus, the experiments are set up to find out what the process is good for under each set of conditions, and also to find out where it is not as efficient as manual processes, so that the report which results may be a guide to more efficient general application. In order to determine the size of library in which the equipment is justified 
a small college library has been included as has a State Library Agency, which we hope will be able to test some small public library operations.

The funds provided by the Carnegie Corporation will pay for the cameras and processors, and for incidental expenses. Each cooperating library will contribute the labor and materials required as well as the time required in planning, in cost studies, and in designing and installing the new routines.

The libraries cooperating in this experiment include five university libraries: Yale University Library, Columbia University Library, University of Chicago Library, University of Illinois Library, and the University of California Library. The three large public libraries participating are the Brooklyn Public Library, The Enoch Pratt Free Library and the Detroit Public Library. Goucher College Library represents the small college libraries; and the Ohio State Library will give us experience in application at the state library level as well as in extension operations. In addition, the Department of Interior Library is cooperating, and is paying its own cost completely, including the cost of the equipment. The author is heading the cooperative project.

The experiments will be conducted over a two year period after which the experience of the group will be summarized in a report on the project. Since the purpose of this experiment is to provide objective data on the basis of generalized experience, the cooperating libraries have agreed that neither the manual nor the results of individual experiments will be published until we have completed the two years ${ }^{1}$ of experimentation in all the cooperating libraries and have prepared our report based on the total experiment.

The cooperating libraries have been making intensive studies of present methods of performing routines. The machines built specially for this project by RemingtonRand have been delivered. The experiments are now under way. We look forward to a very stimulating and instructive two years and hope that the final results may make a contribution to library management.

${ }^{1}$ We are informed that the cooperating libraries have all been working so intensively and enthusiastically that the experimental work will be completed before the end the experimental work will be completed before the end
of 1952 , and a preliminary report, at least, will be ready before the next ALA conference.-[Editor's note]

\section{Eastern College Librarians' Conference}

The Eastern College Librarians' Conference will meet at Columbia University, Saturday, November 29, 1952. The topic for discussion will be "Microtext in the Management of Book Collections." Among the participants in the program will be Sidney Butler Smith, Miles O. Price, Keyes D. Metcalf, Flora Belle Ludington, James T. Babb, Charles F. Gosnell, Ralph R. Shaw, Morris Gelfand, Eileen Thornton, and Donald Cameron. The future pattern of the Conference will also be discussed.

\section{Additions and Corrections to Decimal Classification}

Beginning with the January 1952 issue, the Decimal Classification Section's quarterly publication, Notes and Decisions on the Application of the Decimal Classification started its third series, which includes additions and corrections to the I5th edition, as well as other notes relating to the application of both editions. While some of the notes and decisions in the first two series have been superseded, most of their content is still in force. Issues of Notes and Decisions from 1934 through 1948 may be purchased from the Card Division of the Library of Congress for $\$ 3.45$ a set; from 1949 to date, from the Superintendent of Documents, U. S. Government Printing Office, Washington, D. C., at 30 cents per year. The price of a single issue is ro cents. 